\title{
A Comparison of Cesarean Delivery Outcomes for Rural Family Physicians and Obstetricians
}

\author{
Fay F. Homan, MD, Ardis L. Olson, MD, and Deborah J. Johnson MHA
}

Purpose: Despite declining access to obstetrical care in many regions, family physicians often have difficulty obtaining Cesarean delivery privileges. We compared outcomes of Cesarean deliveries performed by family physicians (FPs) and obstetricians (OBs). The last such study done was more than 15 years ago.

Methods: This study was a chart review of 250 consecutive Cesarean deliveries was done at 2 rural New England hospitals. At one hospital, Cesarean deliveries were performed by FPs; at the other they were done by OBs. Demographics, pregnancy risk factors, and maternal and neonatal complication rates at each site were compared.

Results: Demographics, indications for Cesarean delivery, and prenatal risk factors were comparable at both sites except there were more hypertensive patients at the FP site. There were no differences in intraoperative or infectious complications. There were fewer postoperative complications at the FP hospital, which were mostly attributable to fewer blood transfusions and readmissions. There were no differences in neonatal outcomes, although there were more deliveries of fetuses $<38$ weeks' gestation at the FP site.

Conclusions: Patients did not face increased risk when Cesarean deliveries were performed by FPs rather than OBs. A larger, more geographically diverse study is needed to confirm these findings. Results could support FPs seeking privileges to perform Cesarean deliveries, thus expanding access to care for pregnant women. (J Am Board Fam Med 2013;26:366-372.)

Keywords: Cesarean Section, Maternal Morbidity, Obstetrics, Rural Health Services

Literature comparing outcomes of Cesarean delivery when performed by family doctors compared with obstetricians is limited and dated. The last such study was published 17 years ago, using data collected as far back as $1980 .{ }^{1}$ In some countries, such as Canada, ${ }^{2}$ and in some geographic areas of the United States, ${ }^{3}$ Cesarean deliveries are commonly performed by family physicians. Nationwide, $9.3 \%$ of family doctors perform Cesarean

\footnotetext{
This article was externally peer reviewed.

Submitted 6 August 2012; revised 14 January 2013; accepted 4 February 2013.

From the Dartmouth CO-OP Project, Department of Community and Family Medicine, Geisel School of Medicine at Dartmouth, Hanover, NH.

Funding: This study was conducted with the financial support of the American Academy of Family Physicians Joint Grant Awards Program and support of the Dartmouth CO-OP Practice-Based Research Network faculty.

Conflict of interest: none declared.

Corresponding author: Fay F. Homan, MD, Dartmouth CO-OP Project, Department of Community and Family Medicine, HB 7250, Geisel School of Medicine at Dartmouth, Hanover, NH 03755 (E-mail: Fay.F.Homan@dartmouth.edu).
}

deliveries, $4.4 \%$ independently and $4.9 \%$ in consultation with obstetrics. ${ }^{4}$ However, well-trained family physicians report having difficulty securing hospital privileges to do Cesarean deliveries. ${ }^{3}$ Credentials can be granted or restricted based on committee members' personal opinions, without consideration of physicians' training and experience or scientific data (K. Marvin and L. Desang, personal communications).

Accordingly, the number of family physicians who perform Cesarean deliveries has decreased steadily. ${ }^{5}$ In addition, for a variety of reasons, including malpractice rates and changes in reimbursement, availability of obstetricians in many underserved areas of the United States also has declined. In the northern part of the state of New Hampshire, for example, there are currently no hospitals providing obstetric services (A. Alley, personal communication). ${ }^{6}$ A study that proved the safety of Cesarean deliveries when performed by family doctors could provide support to family phy- 
sicians seeking Cesarean delivery privileges and could thus strengthen the availability of this much needed service to pregnant women in underserved areas. Alternatively, a study that showed concerns about outcomes would be valuable in tailoring and improving the curriculum of family medicine residency and fellowship training programs.

The purpose of this study was to compare the outcomes of Cesarean deliveries at 2 rural New England hospitals, one with family doctors performing Cesarean deliveries (family medicine hospital $[\mathrm{FMH}])$ and the other with obstetricians performing Cesarean deliveries (obstetric hospital $[\mathrm{OBH}])$. The first phase, reported here, is a pilot study in 2 New England community hospitals.

\section{Methods}

\section{Study Design}

The study is a retrospective chart review of consecutive Cesarean deliveries performed in rural hospitals by family physicians and obstetricians. A comparison of the specific complications and total maternal and neonatal complications by category was made between sites.

\section{Study Population}

Two hospitals in small towns in northern New England, with similar average per capita incomes, were recruited to participate. At the FMH, all Cesarean deliveries are performed by 3 family physicians. At the OMH, 6 obstetricians perform Cesarean deliveries. Both are 25-bed critical access hospitals. The $\mathrm{OBH}$ has a designated service area of 30,000 inhabitants; the FMH serves 22,000. Neither is a referral hospital. Both have policies to transfer pregnant patients expected to deliver earlier than 35 weeks' gestation whenever possible. Researchers agreed not to identify clinicians or communities to ensure local cooperation.

The 3 family physicians received training in Cesarean deliveries through different means. One was trained during residency in a program with a strong rural focus. One completed a fourth-year rural obstetrics fellowship program. The third was trained while employed in the National Health Service Corps in Alaska. They had performed 37 to 50 primary Cesarean deliveries and assisted on 75 to 110 before being credentialed at the FMH.

\section{Data Collection}

Data were collected by the lead author (FFH) with assistance of medical student research assistants. The research assistants received training in chart review and data collection techniques and worked under the direct supervision of the principal investigator (FFH). Multiple methods were used to extract data, including review of admission and discharge summaries, prenatal care records, operative reports, intrapartum and intraoperative flow sheets, and billing records. No patient names were collected. Hospital data on the total number of births during the time period was obtained to determine rates of Cesarean deliveries during the data collection period. The study protocol for secondary data collection was approved by Dartmouth University's Institutional Review Board as well as by each hospital.

The 125 most recent consecutive Cesarean deliveries at each hospital were reviewed. Three cases were excluded at the FMH: 2 because the Cesarean deliveries were performed by a temporary obstetrician who briefly covered for a family doctor who was on medical leave, the third was the Cesarean delivery for a patient who was in cardiac arrest at the scene of a motor vehicle accident. The complications in the latter case arose from the motor vehicle accident rather than from the pregnancy or surgery. Because the charts did not have consistent information about the outcome of infants after transfer to newborn intensive care units, newborn death after transfer was not included. Because of differences in obstetrical volume, the data collection period was 60 months at the FMH versus 30 months at the $\mathrm{OBH}$.

Basic maternal demographic data, including age, gravity, parity, insurance status, and race, were obtained to examine the similarity of obstetric populations. Maternal medical conditions were reviewed to determine how prenatal risk factors differed in the 2 populations. Conditions assessed were advanced maternal age ( $\geq 35$ years old), diabetes, hypertension, obesity, excess weight gain, preterm labor, psychiatric illness, smoking, twin gestation, substance abuse (which included use of alcohol, marijuana, narcotics, and buprenorphine), and sexually transmitted infections.

Specific outcomes to be studied were chosen based on previous literature about the subject ${ }^{1}$ and recent data on expected Cesarean deliveries complication rates. ${ }^{7}$ These included intraoperative 
events (eg, Cesarean/hysterectomy, uterine artery laceration, bowel injury, bladder injury); postoperative complications (eg, hemorrhage requiring transfusion, wound dehiscence, return to the operating room, rates of maternal transfer to intensive care unit and readmission); and infectious complications (eg, endometritis, endomyometritis, cellulitis, pneumonia, sepsis, wound infection, and fever $>100.4$ [degrees]F). Neonatal outcomes studied were fetal death, Apgar score, newborn transfer to neonatal intensive care unit, and readmission rates. The process of surgical care was assessed by collecting the following data: (1) "decision to incision" time (in Cesarean deliveries where fetal distress was the indication); American College of Obstetricians and Gynecologists (ACOG) recommends a decision to incision time of $\leq 30$ minutes $^{8}$; (2) length of surgical procedure; and (3) proportion of scheduled Cesarean deliveries meeting the ACOG recommendation ${ }^{9}$ of occurring at $\geq 39.0$ weeks' gestation.

\section{Data Analysis}

The family medicine and obstetric groups were first compared for all variables using the $\chi^{2}$ or Student $t$ test for categorical or continuous variables. Three variables that summed the total complications or risks were calculated to determine whether overall differences existed for pregnancy risks, intraoperative complications, and postoperative complications. Infectious complications were reported separately from postoperative complications. Differences between the 2 sites were calculated for these summative variables by using the $t$ test. When data were not normally distributed, additional nonparametric tests (Mann-Whitney $U$ test) were calculated to confirm if any differences were significant at a 0.05 level. Because nonparametric analyses confirmed all significant parametric analyses, only parametric results are presented here. If $<5$ in any cell of categorical analysis, Fisher exact test rather than $\chi^{2}$ was used. Analyses were conducted using SPSS software (SPSS, Inc., Chicago, IL).

\section{Results}

The rural communities served by the 2 hospitals were similar in socioeconomic status (average income of $\$ 20,000$ at both hospitals). ${ }^{10}$ Table 1 shows that the population characteristics of women at the 2 sites were similar in age, parity, and insur-
Table 1. Demographic Indicators of Study Population

\begin{tabular}{lccc}
\hline & $\begin{array}{c}\text { Family } \\
\text { Medicine } \\
(\mathrm{n}=125)\end{array}$ & $\begin{array}{c}\text { Obstetrics } \\
(\mathrm{n}=125)\end{array}$ & $P$ \\
\hline Demographics & $26.2 \pm 5.4$ & $27.2 \pm 5.1$ & .14 \\
Age, years (mean $\pm \mathrm{SD})$ & $2.25 \pm 1.3$ & $2.23 \pm 1.3$ & .88 \\
Pregnancies (mean $\pm \mathrm{SD})$ & $0.78 \pm 0.97$ & $0.75 \pm 1.0$ & .76 \\
Prior births (mean $\pm \mathrm{SD})$ & & & \\
Insurance & $59(47.2)$ & $72(58.1)$ & .2 \\
$\quad$ Public & $62(49.6)$ & $50(40.3)$ & \\
Private & $4(3.2)$ & $2(1.6)$ & \\
Self-pay & $0(0)$ & $1(0.8)$ & \\
$\quad$ Not specified & & & \\
Race & $116(95.9)$ & $120(96.8)$ & .71 \\
$\quad$ White & $5(4.0)$ & $4(0.8)$ & \\
Asian/Hispanic/Native & & & \\
$\quad$ American & $4(3.2)$ & $1(0.8)$ & \\
$\quad$ Not specified & &
\end{tabular}

Values are n (\%) unless otherwise indicated.

$\mathrm{SD}$, standard deviation.

ance status. Rates of Cesarean deliveries at the 2 hospitals also were similar, with $24 \%$ at the $\mathrm{OBH}$ and $22 \%$ at the FMH.

The average number of prenatal risk factors did not differ between the 2 hospitals. For most measures of prenatal risks, including gestational diabetes, smoking, multiple gestation, psychiatric disorder, and obesity, the study groups were similar (Table 2). Of note, the FMH had more patients with hypertension (14.4\% FPH vs. $5.6 \% \mathrm{OBH}$; $P=.02$, Fisher exact test). Average gestational age at delivery was similar at both hospitals (39.2 weeks at the FMH, 39.1 weeks at the $\mathrm{OBH} ; P=.6, t$ test). There was marked similarity in the indication for Cesarean delivery at the 2 hospitals (Table 3 ). In examining maternal outcomes, there were no maternal deaths and few intraoperative complications at either hospital, with no differences identified (Table 4).

While infectious complications (cellulitis, endometritis or endomyometritis, fever, wound infection, pneumonia, and sepsis) were uncommon, the rates were similar at each hospital. Table 4 shows that there were significantly fewer postoperative complications at the FMH (mean, 0.03 at the FMH vs. 0.12 at the $\mathrm{OBH} ; P=.03$ ). The specific complications are listed in Table 4. Length of stay for mothers following Cesarean delivery was longer at the FMH compared with the $\mathrm{OBH}$ (3.0 vs. 2.6 days; $P<.01)$. 
Table 2. Prenatal Risk Factors

\begin{tabular}{|c|c|c|c|}
\hline Risk Factors & $\begin{array}{l}\text { Family Medicine } \\
\quad(\mathrm{n}=125)\end{array}$ & $\begin{array}{l}\text { Obstetrics } \\
(\mathrm{n}=125)\end{array}$ & $P$ \\
\hline $\begin{array}{l}\text { Total prenatal risks } \\
\quad(\text { mean } \pm \mathrm{SD})\end{array}$ & $0.77 \pm 2.1$ & $0.44 \pm 1.2$ & .61 \\
\hline Advanced maternal age & $10(8)$ & $11(8.8)$ & .82 \\
\hline \multicolumn{4}{|l|}{ Diabetes } \\
\hline All types & $16(12.8)$ & $14(11.2)$ & .70 \\
\hline Gestational & $13(11)$ & $13(10)$ & \\
\hline Type 1 & $0(0)$ & $1(1)$ & \\
\hline Type 2 & $3(2)$ & $0(0)$ & \\
\hline \multicolumn{4}{|l|}{ Hypertension } \\
\hline All types & $18(14.4)$ & $7(5.6)$ & .02 \\
\hline Pregnancy Induced & $12(11)$ & $7(5)$ & \\
\hline Chronic Hypertension & $6(5)$ & $0(0)$ & \\
\hline Obesity & $60(48)$ & $54(43.2)$ & .45 \\
\hline Excess weight gain & $76(62.8)$ & $70(56)$ & .55 \\
\hline Preterm labor & $4(3.2)$ & $6(4.8)$ & .52 \\
\hline Psychiatric illness & $31(24.8)$ & $23(18)$ & .22 \\
\hline Smoking & $35(28.8)$ & $31(25)$ & .89 \\
\hline Twin gestation & $2(2)$ & $2(2)$ & 1.0 \\
\hline Substance abuse & $4(3.2)$ & $8(6.4)$ & .38 \\
\hline Significant other issues*: & $11(8.8)$ & $6(4.8)$ & .31 \\
\hline Chlamydia & 0 & 2 & \\
\hline Coagulopathy & 1 & 2 & \\
\hline IUGR & 2 & 1 & \\
\hline Active herpes & 0 & 1 & \\
\hline PROM & 1 & 1 & \\
\hline Hepatitis C & 2 & 0 & \\
\hline Oligohydramnios & 4 & 0 & \\
\hline
\end{tabular}

Values are $\mathrm{n}(\%)$ unless otherwise indicated.

*Total is $>100 \%$ because of multiple issues per patient.

$\mathrm{SD}$, standard deviation; IGUR, intrauterine growth restrictions; PROM, premature rupture of membranes.

Neonatal outcomes were similar at both hospitals (Table 5). There were no differences in preterm deliveries ( $<37$ weeks' gestation) between hospitals $(6.2 \%$ at the $\mathrm{FPH}$ vs. $7.8 \%$ at the $\mathrm{OBH}$; $P=.4)$. One fetal death at 38 weeks occurred at the $\mathrm{FMH}$ because of amniotic band syndrome with a cord accident.

Data on the surgical process of care is provided in Table 6. While neither hospital met the ACOG goal of $\leq 30$ minutes between the decision to operate and incision, there was a trend toward shorter decision to incision time at the FMH (44 vs. 55.1 minutes; $P=$ .08). Length of the surgery was shorter at the $\mathrm{OBH}$ (42 minutes) compared with the FMH (55 minutes) $(P<.01)$. Another frequently used quality measure is that scheduled Cesarean deliveries should not occur
Table 3. Indications for Cesarean Delivery

\begin{tabular}{lccc}
\hline & $\begin{array}{c}\text { Family } \\
\text { Medicine } \\
(\mathrm{n}=125)\end{array}$ & $\begin{array}{c}\text { Obstetrics } \\
(\mathrm{n}=125)\end{array}$ & $P$ \\
\hline Indications & $21(16)$ & $25(20)$ & .51 \\
Arrest of dilation & $18(14.4)$ & $19(15.2)$ & .86 \\
Arrest of descent & $22(17.6)$ & $20(16.0)$ & .74 \\
$\begin{array}{l}\text { Fetal distress } \\
\text { Scheduled repeat }\end{array}$ & $38(30.4)$ & $40(32.0)$ & .79 \\
$\begin{array}{l}\text { Malpresentation } \\
\text { Placental abruption }\end{array}$ & $12(9.6)$ & $18(14.4)$ & .24 \\
$\begin{array}{l}\text { Elective primary caesarian } \\
\quad \text { section }\end{array}$ & $4(3.2)$ & $0(0)$ & $.12^{*}$ \\
$\begin{array}{l}\text { Placenta previa } \\
\text { Other indications (eg, } \\
\text { macrosomia with } \\
\text { gestational diabetes, } \\
\text { twins, active herpes, } \\
\text { preeclampsia, failed } \\
\text { post-dates induction) }\end{array}$ & $11(8.8)$ & $2(1.6)^{\dagger}$ & 1.0 \\
\hline
\end{tabular}

Values are $\mathrm{n}(\%)$. The totals are greater than $100 \%$ because of multiple indications per patient.

*Fisher's exact test.

${ }^{\dagger}$ One had the relative indication of a prior fourth-degree tear.

The other was a true elective primary section.

before 39.0 weeks. On this measure the 2 hospitals were very similar as well.

\section{Discussion}

Overall, the results of this pilot study show similar Cesarean delivery outcomes in spite of whether a family physician or an obstetrician performed the operation. Although it is a small study, results are reassuring that patients do not face increased risk when having a Cesarean delivery done by a family physician.

Of note was the evidence of fewer noninfectious postoperative complications with a family doctor. This is intriguing but difficult to expand on given the small sample size. This outcome seems to have been influenced by a combination of fewer blood transfusions and fewer readmissions. Fewer transfusions at the FMH could indicate greater attention to treating bleeding intraoperatively (and the longer procedure times may support that). Alternatively, the family physicians may have greater tolerance for a low hematocrit value, which could stem from family medicine practice patterns and training. Likewise, the decreased readmission rate may reflect that family practitioners are more accustomed to outpatient management of medical patients. 


\begin{tabular}{|c|c|c|c|}
\hline Outcomes & $\begin{array}{l}\text { Family Medicine } \\
\quad(\mathrm{n}=125)\end{array}$ & $\begin{array}{l}\text { Obstetrics } \\
(\mathrm{n}=125)\end{array}$ & $P$ \\
\hline \multicolumn{4}{|l|}{ Intraoperative complications } \\
\hline Total $($ mean \pm SD) & $0.02 \pm 0.18$ & $02 \pm 0.20$ & 1.0 \\
\hline Caesarian section/hysterectomy for placenta accreta & 0 & 1 & \\
\hline Uterine artery laceration & 1 & 0 & \\
\hline Cervical laceration & 0 & 1 & \\
\hline Intraoperative hematuria, no source & 1 & 0 & \\
\hline \multicolumn{4}{|l|}{ Infectious complications } \\
\hline Total $($ mean $\pm \mathrm{SD})$ & $0.03 \pm 0.18$ & $0.04 \pm 0.20$ & .74 \\
\hline Endometritis or endomyometritis & 1 & 5 & \\
\hline Transient fever to $100.4^{\circ} \mathrm{F}$ & 2 & 0 & \\
\hline Fever/UTI & 1 & 0 & \\
\hline \multicolumn{4}{|l|}{ Postoperative complications } \\
\hline Total $($ mean $\pm \mathrm{SD})$ & $0.03 \pm 0.18$ & $0.12 \pm 0.41$ & .03 \\
\hline ICU transfer & 0 & 2 & \\
\hline Return to operating room & 0 & 1 & \\
\hline Transfusion & 1 & 5 & \\
\hline \multicolumn{4}{|l|}{ Readmission for pregnancy-related diagnosis } \\
\hline & 2 & 7 & \\
\hline Readmission for other diagnosis & 1 & 0 & \\
\hline Maternal length of stay (mean \pm SD) & $3.0 \pm 0.68$ & $2.6 \pm 0.87$ & $<.01$ \\
\hline
\end{tabular}

Values are $\mathrm{n}$ unless otherwise indicated.

ICU, intensive care unit; UTI, urinary tract infection.

The strikingly similarity in rates and indications of Cesarean deliveries suggests that obstetric practice patterns and decision making were similar between the 2 groups. The baseline health status of the patients was similar for most measures. However, higher rates of hypertension suggested slightly more complex patients at the FMH.

Table 5. Newborn Outcomes

\begin{tabular}{|c|c|c|c|}
\hline Outcomes & $\begin{array}{c}\text { Family } \\
\text { Medicine } \\
(\mathrm{n}=125)\end{array}$ & $\begin{array}{l}\text { Obstetrics } \\
(\mathrm{n}=125)\end{array}$ & $P$ \\
\hline \multicolumn{4}{|l|}{ Gestational age (weeks) } \\
\hline$<37.0$ & $8(6.2)$ & $10(7.8)$ & .40 \\
\hline$\geq 37.0$ & $120(93.8)$ & $118(92.2)$ & \\
\hline \multicolumn{4}{|l|}{ Apgar score } \\
\hline 1 minute & $8.0 \pm 1.8$ & $8.0 \pm 1.6$ & .80 \\
\hline 5 minutes & $8.7 \pm 1.3$ & $8.8 \pm 1.1$ & .68 \\
\hline Length of stay & $3.0 \pm 0.89$ & $2.9 \pm 1.3$ & .21 \\
\hline $\begin{array}{l}\text { Transfer to neonatal } \\
\text { intensive care unit }\end{array}$ & $5(3.9)$ & $8(6.3)$ & .22 \\
\hline $\begin{array}{l}\text { Fetal death at community } \\
\text { hospital }\end{array}$ & $1^{*}$ & $0^{*}$ & 1.0 \\
\hline Readmission & $3(2.3)$ & $7(5.5)$ & .35 \\
\hline
\end{tabular}

Values are $\mathrm{n}(\%)$ or mean \pm standard deviation.

*See narrative.
The longer surgical times at the FMH may be due to the relative infrequency of surgery performed by the family practitioners compared with the obstetricians. There are at least theoretical risks involved with longer surgical times, including infection and anesthetic complications. However, our data does not show evidence of any increased risk. The trend toward faster decision to incision time at the FMH, 11 minutes faster on average, would likely offset any increased risk to the fetus due to slower surgical operators. In future studies, a more valuable data point might be to document incisionto-delivery or decision-to-delivery times in terms

Table 6. Cesarean Section Quality Indicators

\begin{tabular}{lccr}
\hline Indicators & Family Medicine & Obstetrics & $P$ \\
\hline $\begin{array}{c}\text { Decision to incision } \\
\text { time (minutes) }\end{array}$ & $44.0 \pm 16.8$ & $55.1 \pm 22.5$ & .08 \\
$\begin{array}{c}\text { Total surgical time } \\
\text { (minutes) }\end{array}$ & $55.2 \pm 14.7$ & $42.5 \pm 13.7$ & $<.01$ \\
$\begin{array}{c}\text { Scheduled at } \geq 39 \\
\text { weeks }^{\dagger}\end{array}$ & $29 / 32(91 \%)$ & $26 / 32(82 \%)$ & .47 \\
\hline
\end{tabular}

*Only cases in which fetal distress is an indication for surgery: 22 cases at family medicine site, 20 cases at obstetrics site.

${ }^{\dagger}$ Only cases for which a Cesarean section was scheduled. 
of measuring risk to infants in fetal distress. In terms of minimizing risk to the fetus, the data also suggest that quality efforts focused on improving decision to incision times might provide the most benefit.

The increased length of stay for mothers at the FMH does not seem to be attributable to sicker patients and may simply represent a difference in cultural norms of the 2 hospitals. Although increased cost may be associated with the longer hospital stay, in this case it may be offset by or even partially responsible for the decreased readmission rates.

Although postoperative maternal complications were lower at the FMH, for most measures both hospitals had complication rates that compared favorably to published standards. For instance, blood transfusion after Cesarean delivery is expected to be $2 \%$ to $3 \% .^{7}$ Our hospitals were similar, with $4 \%$ transfusion at the $\mathrm{OBH}$ and $1 \%$ at the FMH. Infection of the surgical site in one large case-control study was found to be $5 \% .^{7}$ In our study, the infection rate at the obstetric hospital was $4 \%$; it was $3 \%$ at the family medicine hospital.

Moreover, rates of Cesarean deliveries at both study hospitals were low: $22 \%$ at the FMH and $24 \%$ at the OBH, compared with the national average of $32 \%{ }^{11}$ and the New Hampshire rate of $32.5 \% .^{12}$ Therefore, patients in this study were subjected to less surgical risk overall than patients in other geographic areas, regardless of whether their Cesarean delivery was performed by a family physician or an obstetrician.

There are limitations that need to be noted. This was a small, exploratory study. It is recognized that the baseline frequency for some outcomes is so low that achieving statistical significance is unlikely (ie, maternal and fetal death). The principal investigator for the study (FFH) is one of the physicians at the FMH; she established the methodology for the data collection, which then was performed in part by medical students and in part by the principal investigator herself. This could introduce unintentional bias in data collection. While this is reasonable methodology for the purpose of a small pilot study, it would need to be refined for a follow-up study. In addition, this study was conducted in only one geographical region. Maternal outcomes could be meaningfully addressed by major categories only because the occurrence of specific complications or baseline frequency for some outcomes was so low that achieving statistical signifi- cance was unlikely (eg, maternal and fetal death). To address these issues, a subsequent larger study with more geographic diversity and better ability to detect rare complications will need to occur.

This study supports the hypothesis that the specialty of the surgical operator does not affect patient risk. Although this is the position of both the American Academy of Family Physician and ACOG, ${ }^{13}$ family physicians often find Cesarean delivery privileges difficult to obtain. ${ }^{3,5}$ The results of this exploratory study agree with earlier work ${ }^{1}$ that there is no increased overall risk to patients if a family doctor performs a Cesarean delivery and support family medicine physicians seeking such privileges. This in turn, stands to improve maternal child health in underserved areas by ensuring access to obstetric care.

The authors acknowledge Abbi Hoke, Tom Hoke, Emily Looney, Gaelan Murphy, Melody Scheefer, Amy Thomas, and the medical records departments at the 2 participating hospitals.

\section{References}

1. Deutchman M, Connor P, Gobbo R, FitzSimmons R. Outcomes of Cesarean sections performed by family physicians and of the training they received: a 15-year retrospective study. J Am Board Fam Pract 1995;8:81-90.

2. Iglesias $S$, Hutten-Czapski P. Joint position paper on training for rural family practitioners in advanced maternity skills and Cesarean section. College of Family Physicians of Canada, Society of Rural Physicians of Canada, Society of Obstetricians and Gynaecologists of Canada. CJRM 1999;4:209-16.

3. Chang Pecci C, Leeman L, Wilkinson J. Family medicine obstetrics fellowship graduates: training and post-fellowship experience. Fam Med 2008;40: 326-32.

4. American Academy of Family Physicians. Table 17. Provision of selected services and procedures in hospital practices of family physicians (as of April 2011). Available from: http://www.aafp.org/online/en/home/ aboutus/specialty/facts/17.html. Accessed May 15, 2013.

5. American Academy of Family Physicians. Privileges, family medicine departments. Available from: http://www.aafp.org/online/en/home/policy/policies/ p/fammeddeptprivileges.html. Accessed May 15, 2013.

6. Berghella V. Cesarean delivery: postoperative issues. Available from: http://www.uptodate.com/contents/ Cesarean-delivery-preoperative-issues. Accessed May 15, 2013.

7. Standards for obstetric-gynecologic services. In: American College of Obstetricians and Gynecolo- 
gists, ed. Guidelines for women's health care: a resource manual. Washington, DC: ACOG; 1996.

8. American College of Obstetricians and Gynecologists. ACOG Practice Bulletin No. 97: fetal lung maturity. Obstet Gynecol 2008;112:717-26.

9. US Census Bureau. State and county quick facts: New Hampshire. Available from: http://quickfacts. census.gov/qfd/states/33000.html. Accessed May 5, 2013.

10. Hamilton BE, Martin JA, Ventura SJ, Division of Vital Statistics. Births: preliminary data for 2007.

Natl Vital Stat Rep 2009;57:1-23. Hyattsville, MD: National Center for Health Statistics. Available from: http://www.cdc.gov/nchs/data/nvsr/nvsr57/ nvsr57_12.pdf. Accessed May 15, 2013.

11. State of New Hampshire Insurance Department. A commercial insurance study of vaginal delivery and Cesarean delivery rates at New Hampshire hospitals. April 1, 2011. Available from: http://www.nh.gov/ insurance/reports/documents/commins_stdy_delivery. pdf. Accessed May 15, 2013.

12. AAFP-ACOG joint statement on cooperative practice and hospital privileges. American Academy of Family Physicians. American College of Obstetricians and Gynecologists. Am Fam Physician 1998;58:277-8. 